\title{
Spatial-temporal Pattern of Water requirement in Xiliaohe Watershed
}

\author{
Rui Wang, Jiquan Zhang*, Feng Zhang, Enliang Guo, Meng Zhu, Danjun Li
}

School of Environment, Northeast Normal University, Institute of Natural Disaster Research, Northeast Normal University, Changchun 130024, China

\section{西辽河流域春玉米需水量时空演变}

王濰, 张继权”, 张峰, 郭恩亮, 朱萌, 李丹君

东北师范大学环境学院, 东北师范大学自然灾害研究所, 长春 130024 , 中国

\begin{abstract}
Based on the climatic data from 23 meteorological stations throughout the Xiliaohe watershed during 1961 and 2010, every month's spring maize water requirement are calculated by Penman-Monteith model, In addition, Spatial distribution of water requirement in Xiliaohe watershed can be analyzed using the Mann-Kendall and Ordinary Kriging method. Conclusions are as follows: Water requirement in Xiliaohe watershed is positive correlation relationship with T-max, mean wind speed and hours of sunshine. It's negative correlated relationship with relative average humidity; As a whole, water requirement in the study area is on the decline. Every month's spring maize water requirement first increased and then decreased. Water requirement is highest in July and is lowest in May; The spatial distributional trend of water requirement is that water requirement decreased from mid-east region to all around. Water requirement is larger, the crop take more risk.
\end{abstract}

Keywords: Crop water requirement; PenmanMonteith model; Mann-Kendall; spatial interpolation; Xiliaohe watershed

\section{摘要}

利用西辽河流域及其周边 23 个站点

*通讯作者：张继权，Zhangjq022@nenu.edu.cn
1961-2010 年的气象资料 (最高温度、最低温 度、平均相对湿度、平均风速和日照时数等), 采用 Penman-Monteith 模型对研究区春玉米各 生育期需水量进行计算, 并通过 Mann-Kendall 检验法和普通克里格空间插值法对西辽河流 域需水量进行时空演变分析。结果表明: 西辽 河流域需水量与最高气温、平均风速、日照时 数呈正相关关系, 与平均相对湿度呈负相关关 系; 研究区 50a 需水量整体呈下降趋势, 各生 育期需水量呈先增加后减少的趋势, 5 月需水 量最低, 7 月需水量最高; 西辽河流域需水量 空间分布呈以呈中-中东部高值区向四周呈辐 射状递减的趋势, 需水量过大, 会造成该地区 水资源存在潜在安全隐患。

关键词: 作物需水量; Penman-Monteith 模型; Mann-Kendall; 空间插值; 西辽河流域

\section{1. 引言}

水是人类赖以生存的物质基础, 随着社会经济 的增长和人们生活水平的日益提高, 水资源的 供需矛盾日益突出, 这不但威胁着人类用水安 全问题, 还影响作物的正常生长。西辽河流域 在区域和国家粮食安全中具有重要的地位, 近 年来西辽河流域的取、用水量不断增加, 频繁 出现河流断流现象、林木草场的矮化和退化等 环境问题 ${ }^{[1]}$, 因此该地区水资源供需情况及变 化趋势备受人们的关注。

作物需水量(Crop Water Requirement), 是 指生长在大面积上的无病虫害作物, 土壤水分 和肥力适宜时, 在给定的生长环境中能取得高 产潜力的条件下, 为满足植株蒸腾、棵间蒸发、 


\section{Risk Analysis and Crisis Response in Big Data Era (RAC-16)}

组成植株体的水量之和 ${ }^{[2]}$ 。目前有关作物需水 量计算的研究方法很多, 总体上可以分为三大 类：第一类是“惯用法”，对于干旱作物需水 量的计算常采用以产量为参数的经验公式, 但 是此方法对于水稻等的计算误差较大。积温法 常被应用在水稻需水量的计算, 日照时数法适 用于太阳辐射比较稳定的夏季生长的作物需 水量的计算 ${ }^{[3-6]}$; 第二类是直接计算作物需水 量法, 主要包括水面蒸发法和水量平衡法。第 三类是通过参考作物需水量计算实际作物需 水量, 通常采用彭曼综合法, 该方法已成为计 算参考作物需水量的主要方法 ${ }^{[7]}$ 。本文拟采用 Mann-Kendall 趋势检验法和克里金空间插值 发, 揭示西辽河流域春玉米需水量的时空变化 趋势, 并分析了需水量和各气象因子的相关性。 以期为该地区水资源利用研究提供基础数据,
为未来农业用水规划提供参考依据。

\section{2. 材料与方法}

\section{1. 区域概况及数据来源}

西辽河流域介于 $116^{\circ} 32^{\prime} \mathrm{E} \sim 124^{\circ} 30^{\prime} \mathrm{E}$, $41^{\circ} 05^{\prime} \mathrm{N} \sim 45^{\circ} 13^{\prime} \mathrm{N}$, 地处中国北方农牧交错带 的东段三北交界区 ${ }^{[8]}$ 。该区域属于暖温带半湿 润气候向中温带半干旱气候的过渡带, 具有强 烈的大陆性特征, 年平均气温为 $5.0 \sim 6.5^{\circ} \mathrm{C}$, 年平均降水介于 $330 \sim 550 \mathrm{~mm}$ 之间 ${ }^{[9]}$ 。本文选 取西辽河流域及其周边的 23 个地面气象台站 50 年的气象数据, 气象数据来源于中国气象 科学数据共享服务网, 包括最高气温、最低气 温、相对湿度、平均风速和日照时数等, 时间 序列为 1961-2010 年, 研究区地理位置及气象 台站分布如图 1 所示。

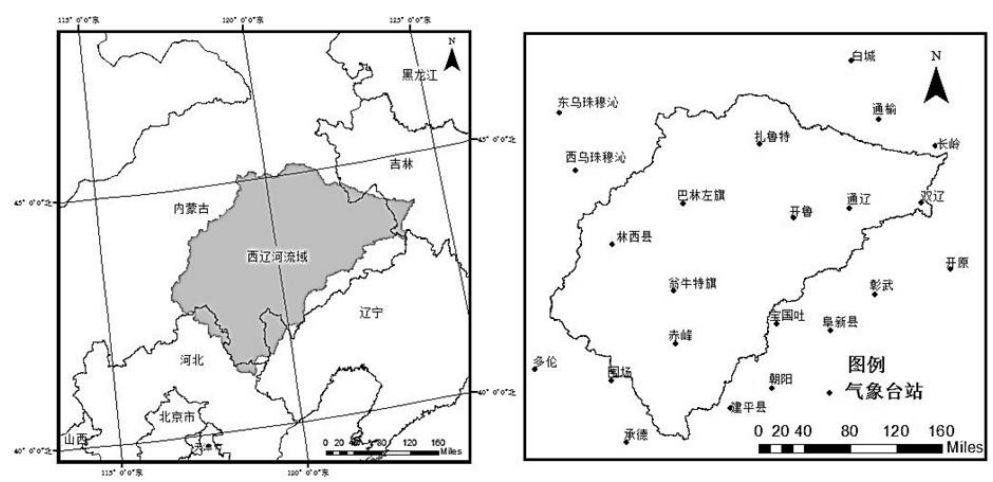

图 1 西辽河流域地理位置及气象台站分布图

\section{2. 研究方法}

\subsubsection{FAO Penman-Monteith 模型}

1998 年, 联合国粮农组织（FAO）对 Penman-Monteith 模型进行修正, 得到 Penman-Monteith(98)模型, 该方法相对误差较 小, 得到国内外学者的广泛应用 ${ }^{[10]}$ 。本文选用 Penman-Monteith(98)模型对 ET0 进行计算, 计 算公式如下:

$$
E T_{C}=\frac{0.408\left(R_{n}-G\right)+r \frac{900}{T+273} U_{2}\left(\mathrm{e}_{\mathrm{s}}-\mathrm{e}_{\mathrm{a}}\right)}{\Delta+\mathrm{r}\left(1+0.34_{2}\right)}
$$

式中: ET0 为参考作物蒸散量 $(\mathrm{mm} / \mathrm{d}) ; \Delta$ 为 饱和水汽压曲线斜率 $\left(\mathrm{KPa} /{ }^{\circ} \mathrm{C}\right) ; \mathrm{Rn}$ 为地表净 辐射 $(\mathrm{MJ} /(\mathrm{m} 2 \cdot \mathrm{d})) ; \mathrm{G}$ 为土壤热通量 $(\mathrm{MJ} /$ $(\mathrm{m} 2 \cdot \mathrm{d})) ; \mathrm{r}$ 为干湿表常数; $\mathrm{T}$ 为 $2 \mathrm{~m}$ 高处日
均气温 $\left({ }^{\circ} \mathrm{C}\right) ; \mathrm{U} 2$ 为 2 米高处风速 $(\mathrm{m} / \mathrm{s})$; es 为饱和水汽压 $(\mathrm{KPa})$; ea 为实际水汽压 $(\mathrm{KPa})$ 。 作物需水量系指在不考虑植株体水量及其他 复杂的影响因素时, 为了使作物获得最高产量 所需要的水分 ${ }^{[7]}$ 。其公式如下:

$$
E T_{\mathrm{c}}=K_{\mathrm{c}} \times E T_{0}
$$

式中 $\mathrm{ETc}$ 为作物需水量 $(\mathrm{mm} / \mathrm{d}) ; \mathrm{ET}_{0}$ 为作物 潜在蒸散量; $\mathrm{Kc}$ 为作物系数, 由于西辽河流 域春玉米的生长期为 5 月 1 日-9 月 27 日, 因 此本文依据农业速查速算手册确定春玉米生 育期的 $\mathrm{Kc}$ 值 ${ }^{[11]}$, 如表 1 所示。 
Risk Analysis and Crisis Response in Big Data Era (RAC-16)

表 1 西辽河流域各生育期春玉米 $\mathrm{Kc}$ 值

\begin{tabular}{cccccc}
\hline 5 月 & 6 月 & 7 月 & 8 月 & 9 月 & 全生育期平均 \\
\hline 0.2 & 0.58 & 1.57 & 1.61 & 0.66 & 0.89 \\
\hline
\end{tabular}

2.2.2. Mann-Kendall 检验法

Mann-Kendall 检验法广泛应用于气象、水文学 中, 具有计算简便、突变时间明显且能直接判 断其显著情况等优点 ${ }^{[12-14]}$ 。本文基于该方法对 西辽河流域春玉米的需水量进行趋势和突变 分析, 其计算式如下:

$$
S_{K}=\sum_{\mathrm{i}=1}^{\mathrm{k}} \sum \boldsymbol{\alpha}_{\mathrm{j}} \quad(\mathrm{k}=2,3,4, \ldots, \mathrm{n})
$$

其中,

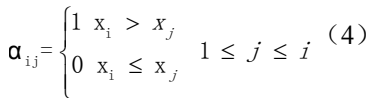

定义统计量 UFK 为:

$$
\mathrm{UF}_{\mathrm{k}}=\frac{\left[S_{K}-E\left(S_{K}\right)\right]}{\sqrt{\operatorname{var}\left(S_{k}\right)}} \quad(\mathrm{k}=2,3,4, \ldots, \mathrm{n})(5)
$$

其中，

$$
\begin{aligned}
& \mathrm{E}\left(\mathrm{S}_{K}\right)=\mathrm{K}(\mathrm{K}+1) / 4 \\
& \operatorname{Var}\left(S_{K}\right)=K(K-1)(2 K+5) / 72
\end{aligned}
$$

将时间序列 $\mathrm{x}$ 按逆序排列, 重复上述过程, 使

$$
\left\{\begin{array}{l}
\mathrm{UB}_{\mathrm{k}}=-\mathrm{UF}_{K} \\
\mathrm{~K}=\mathrm{n}+1-\mathrm{k}
\end{array} \quad(\mathrm{k}=2,3,4, \cdots, \mathrm{n})(8)\right.
$$

式中, UFk 为标准正态分布, 给定显著性水平 $\alpha$, 若 $\left|U_{\mathrm{i}}\right|>\mathrm{U}_{\alpha / 2}$ 时, 则表示存在明显的趋势

变化。UFi $>0$ 时, 呈上升趋势; $U F i<0$ 时, 呈

下降趋势。

\subsubsection{CI 空间插值法}

空间插值法有 IC (先插值再计算) 和 CI（先 计算再插值)两种, 依据前人的研究经验可知, 后者的精度更高 ${ }^{[15,16]}$ 。因此本研究运用 ArcGIS 软件中的普通克里格法对已有站点的数据进 行 CI 空间插值，计算得到西辽河流域 50 年间 逐月需水量，并分析其时空分布情况。

\section{3. 结果与分析}

\section{1. 需水量与气象要素相关性分析}

本文对西辽河流域 5-9 月的需水量与各气象要 素进行了相关性分析。结果显示 (表 2), 西 辽河流域的需水量与平均相对湿度的相关性 最大, 在春玉米整个生育期内, 其相关性均超 过了 $95 \%$ 的显著性水平，在 6、7、9 月超过了 99\%的显著性，这说明西辽河流域对需水量影 响最大的是平均相对湿度, 且呈负相关的关系。 与此同时, 西辽河流域的需水量与最低温度的 关系不显著，在 5、7、9 月呈负相关关系，6、 8 月呈正相关关系。最高温度、平均风速、日 照时数的相关性较强, 均呈正相关的关系, 最 高温度和日照时数对需水量的影响基本一致, 均在 $6 、 7 、 8$ 月中较为明显, 平均风速在 5 、 6、9 月的影响较大。综上所述, 最高温度、 平均相对湿度、平均风速和日照时数是影响西 辽河流域春玉米需水量的主要因素, 因此更好 的缩小作物需水量, 提高农作物用水安全, 应 根据气候变化做出相应的对策。

表 2 西辽河流域需水量与各气象要素之间的相关系数 $(r)$

\begin{tabular}{llcccl}
\hline 月份 & 最高温度 $\left({ }^{\circ} \mathrm{C}\right)$ & 最低温度 $\left({ }^{\circ} \mathrm{C}\right)$ & 平均相对湿度 $(\%)$ & 平均风速 $(\mathrm{m} / \mathrm{s})$ & 日照时数 $(\mathrm{h})$ \\
\hline 5 & 0.095 & -0.080 & $-0.347^{*}$ & $0.326^{*}$ & 0.251 \\
6 & $0.341^{*}$ & 0.115 & $-0.376^{* *}$ & $0.340^{*}$ & $0.406^{*}$ \\
7 & $0.384^{* *}$ & -0.055 & $-0.484^{* *}$ & 0.249 & $0.566^{* *}$ \\
8 & $0.396^{* *}$ & 0.029 & $-0.353^{*}$ & 0.172 & $0.287^{*}$ \\
9 & 0.043 & -0.120 & $-0.363^{* *}$ & $0.475^{* *}$ & 0.204 \\
\hline
\end{tabular}

*表示在 0.05 水平上显著相关; **表示在 0.01 水平上显著相关 


\section{Risk Analysis and Crisis Response in Big Data Era (RAC-16)}

\section{2. 西辽河流域及其站点全生育期需水量时 间变化特征}

西辽河流域 50a 来需水量变化呈锯齿状(图 2), 这表明该地区需水量变化较为剧烈, 但整体上 呈下降的趋势, 需水量范围在 284-654mm 之 间,最高值出现在 1963 年,最低值出现在 2005 年。为了进一步研究各个站点的变化情况, 采 用 Mann-Kendall 趋势分析法对西辽河流域及 各站点全生育期的春玉米需水量时间变化趋 势进行分析, 表 3 中可以看出, 除锡林浩特、
通辽、通榆 3 个站点需水量呈上升趋势外, 其 余 20 个站点均呈现下降的趋势，其上升、下 降的趋势均未超过 0.05 显著性水平，这说明 研究区时间变化趋势不显著。宝国吐、白城、 建平县和朝阳 4 个站点的 UF 绝对值均大于 0.88 , 相对于其他站点而言, 需水量下降趋势 较为明显。西辽河流域的 UF 值为 -0.396 , 呈 现下降趋势, 这与图 3 的线性趋势分析结果一 致，总体而言 50a 间西辽河流域的需水量呈现 整体下降的趋势。

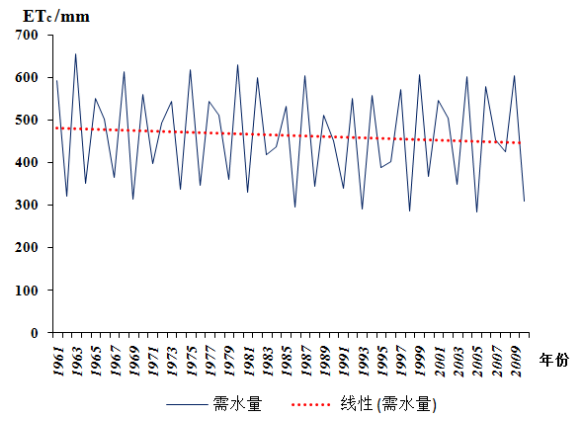

图 2 1961-2010 年西辽河流域需水量变化趋势

表 3 1961-2010 年西辽河流域及各站点需水量变化趋势（M-K）

\begin{tabular}{cccccc}
\hline 站点名称 & $\mathrm{UF}$ & 站点名称 & $\mathrm{UF}$ & 站点名称 & $\mathrm{UF}$ \\
\hline 彰武 & -0.257 & 多伦 & -0.495 & 宝国吐 & -0.882 \\
长岭 & -0.092 & 动物珠穆沁 & -0.560 & 白城 & -0.884 \\
赤峰 & -0.275 & 翁牛特旗 & -0.605 & 建平县 & -0.886 \\
围场 & -0.280 & 阜新县 & -0.606 & 朝阳 & -0.909 \\
开鲁 & -0.294 & 扎鲁特 & -0.610 & 锡林浩特 & 0.027 \\
西乌珠穆沁 & -0.396 & 双辽 & -0.654 & 通辽 & 0.216 \\
林西县 & -0.436 & 开原 & -0.662 & 通榆 & 0.292 \\
巴林左旗 & -0.465 & 承德 & -0.694 & & \\
\hline 西辽河流域 & -0.396 & & & &
\end{tabular}

\section{西辽河流域 \\ 3.3. 西辽河流域春玉米需水量空间分析}

对西辽河流域各生育期多年平均需水量进行 空间插值, 可知西辽河流域需水量具有明显的 空间差异性，空间上呈中-中东部高值区向四 周呈辐射状递减。从县域尺度来看, 整体呈现 以科尔沈沙地为中心区域向东北、西南两侧减 少的趋势。自西辽河流域西南方向围场-林西 县-巴林左旗-翁牛特, 至东北方向巴林左旗扎鲁特-开鲁-通辽-双辽, 随着地形地貌的影响, 研究区的海拔逐渐降低, 加之纬度、温度和降
水等条件的约束, 春玉米各生育期需水量呈现 先升高再降低的规律, 5 月需水量最低, 其值 范围在 21.13 28.07 $\mathrm{mm}$ 之间, 之后随之增加, 7 月达到峰值, 其值范围在 142.33 178.99mm, 之后随之降低。开鲁县地处西辽河冲积平原西 部, 该区域气温变化不大, 地势较为平坦, 海 拔高度为 $243 \mathrm{~m}$, 相对湿度较小, 该区域春玉 米各生育期需水量均最高, 在需水量较高的季 节和区域, 玉米存在较大的风险, 易造成粮食 减产、绝产等较为严重的问题。 


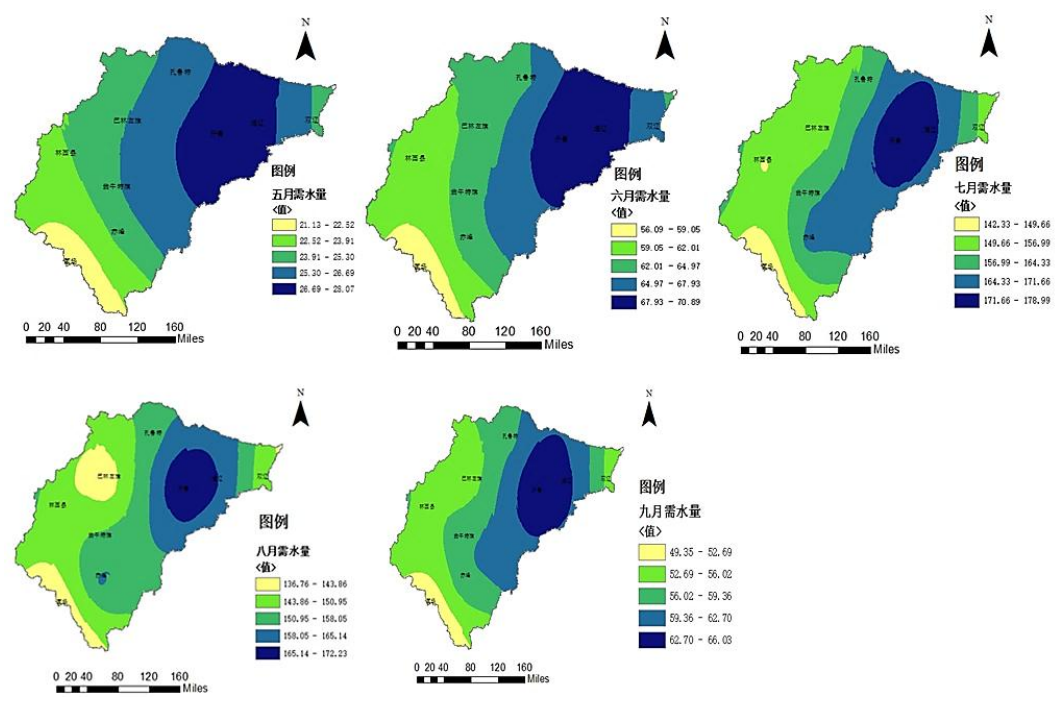

图 3 西辽河流域生育期各月春玉米需水量空间分布图

\section{4. 结论与讨论}

\section{1. 结论}

本文选取 1961-2010 年西辽河流域 23 个站点 气象数据进行需水量计算, 并采用相关分析、 Mann-Kendall 检验法和普通克里格空间插值 法对研究区进行时空格局分析。结果表明:

（1）西辽河流域需水量与最高温度、平均风 速和日照时数呈正相关关系, 各个生育期的需 水量与气象要素之间的相关程度不同, 7 月最 高温度和日照时数与作物需水量的相关性均 超过 $99 \%$ 的显著性水平; 平均相对湿度与需水 量呈负相关关系，且在整个生育期内相关性均

\section{2. 讨论}

西辽河流域地处北方农牧交错带, 随着全球气 候变暖以及玉米播种面积不断增大的影响, 该 区域应重视和加强水资源保护和利用, 尤以科 尔沁沙地为代表。近 50a 来, 西辽河流域全生 育期需水量呈逐年下降的趋势, 这是各个气象 要素（温度、湿度、风速、日照时数等）的共 同影响所致，因此仅考虑个别指标对其的影响 具有一定局限性。本文分析了各气象要素与作 物需水量的相关关系, 客观的分析了 $50 \mathrm{a}$ 间需 水量的变化趋势, 有效的减小了误差。作物需 水量的研究可为区域水资源合理布局及水安 全评价提供科学依据, 对区域农业防御水旱灾 害及其风险评价具有指导意义。
超过 95\%的显著性水平, 其对需水量的影响程 度最大。

(2) 50a 内西辽河流域春玉米全生育期需水量 范围在 284-654mm之间, 逐年呈下降的趋势, 除锡林浩特、通辽、通榆 3 个站点需水量呈上 升趋势外, 其余 20 个站点均呈现下降的趋势, 但上升和下降都不显著。

（3）西辽河流域春玉米需水量空间布局呈以 科尔沁沙地为中心的中-中东部高值区向四周 呈辐射状递减。自西南方向至东北方向, 随着 地形地貌和气象要素的影响, 春玉米各生育期 需水量均呈现先升高再降低的规律。

本文的研究结果与杨艳昭、杨剑等人的结果一 致 ${ }^{[17,18]}$ 。因此, 本文对西辽河流域春玉米需水 量的时空分布特征的探究是科学可靠的, 有利 于该区域农业水资源的开发和利用, 为合理调 度水库以及发展节水灌溉的研究提供了科学 依据与方法支持。本研究也存在不足之处, 文 中仅气象要素的角度分析作物需水量的时空 格局, 未考虑地形地貌特征、人类活动及其它 社会因素对其的影响, 有待进一步研究。

\section{Acknowledgements}

This study was supported by National Natural Science Foundation (41571491), the National Non-Profit Research Program of China 
(No.201401015) and "Twelfth five-year" science and technology support project (2011BAD3 2B00-04).

\section{致谢}

本研究得到了国家自然科学基金项目 (41571491)、水利部公益性行业科研专项经 费项目 (201401015)” 和国家 “十二五” 科技 支撑项目（2011BAD32B04）”的支持。

\section{参考文献}

[1]孙小舟，封志明，杨艳昭. 西辽河流域 1952 年-2007 年参考作物蒸散量的变化趋势. 资源科学, 2009, 31(3):479-484.

[2] R. Zhang, H Zou, M. Hong, et al. Risk analysis of water resources crisis in the Lancang - Mekong River Drainage Basin under the background of climate change. Journal of Risk Analysis and Crisis Response, 2012, 2(3):209-213.

[3] 黄仲冬, 齐学斌, 㚞向阳,等. 降雨和蒸散 对夏玉米灌溉需水量模型估算的影响. 农业工程学报, 2015, 31(5):85-92.

[4] 庞艳梅, 陈超, 潘学标. 1961-2010 年四川 盆地玉米有效降水和需水量的变化特征. 农业工程学报, 2015, 31(z1):133-141.

[5]Conrad C, Rahmann M, Machwitz M. Satellite based calculation of spatially distributed crop water requirements for cotton and wheat cultivation in Fergana Valley, Uzbekistan. Global \& Planetary Change, 2013, 110(4):88-98.

[6]焚引琴. 作物蒸发蒸腾量的测定与作物需 水量计算方法的研究[D]. 西安: 西北农林 科技大学, 2001 .

[7] 高晓容, 王春乙, 张继权,等. 近 50 年东北 玉米生育阶段需水量及旱涝时空变化. 农业工程学报, 2012, 28(12):101-109.

[8]Hao L, Zhang X, Gao J. simulating human-induced changes of water resources in the upper Ciliaohe river basin, China. Environmental Engineering \& Management
Journal, 2011

[9]何俊仕, 边晓东, 付玉娟, 等. 西辽河平原主 要作物耗水量及耗水规律研究. 节水灌 溉, 2012(11):1-4.

[10]吴志勇, 陆桂华, 张建云, 等. 西辽河流域 潜在蒸散量时空格局. 地理科学进展, 2010, 29(9):1115-1120.

[10] 胡志桥, 田霄鸿, 张久东, 等. 石羊河流域主 要作物的需水量及需水规律的研究. 干 旱地区农业研究, 2011, 29(3):1-6.

[11]刘光启.农业速查速算手册 [ M]. 北京:化学 工业出版社,2007:66.

[12]Shadmani M, Marofi S, Roknian M. Trend Analysis in Reference Evapotranspiration Using Mann-Kendall and Spearman's Rho Tests in Arid Regions of Iran. Water Resources Management, 2012, 26(1): 211224.

[13]张涵丹, 卫伟, 薛萐. 基于 $\mathrm{R} / \mathrm{S}$ 分析和 Mann-Kendall 检验的定西市气温降水变 化特征. 水土保持研究, 2015, 22(6):183-189.

[14]雷璐，孙春敏. Mann-Kendall 检验方法在 增江径流趋势分析中的应用. 中国科技 信息，2012(19):39-39.

[15]Stein A, Staritsky I G, Bouma J, et al. Simulation of moisture deficits and areal interpolation by universal cokriging.. Water Resources Research, 1991, 27(8): 19631973.

[16]Bechini L, Ducco G, Donatelli M, et al. Modelling interpolation and stochastic simulation in space and time of global solar radiation. Agriculture Ecosystems \& Environment, 2000, 81(1):29-42.

[17]杨艳昭, 杨玲, 张伟科, 等. 西辽河流域玉 米水分平衡时空分布格局. 干旱区资源 与环境, 2014, 28(4).

[18]杨剑, 孙小舟. 西辽河流域春玉米需水量 变化趋势. 华中师范大学学报: 自然科学 版, 2010, 44(4):691-695. 